\title{
Experimental Research on Optimization for Performance of Pervious Concrete
}

\author{
Liangying $X \mathrm{U}^{1, \mathrm{a}}$, Tongyuan $\mathrm{NI}^{2,3, * b}$, Yang $\mathrm{YANG}^{2,3, * c}$, Jingru $\mathrm{YU}^{2, \mathrm{~d}}$, \\ Jintao Liu ${ }^{2,3, ~ e, ~ C h u n p i n g ~ G U 2, ~ 3, ~ f ~}$ \\ ${ }^{1}$ Hangzhou CBD Investment Group Co. Ltd. Hangzhou, China, 310020; \\ ${ }^{2}$ College of Architecture \&Civil Engineering, Zhejiang University of Technology, Hangzhou, China, \\ 310032; \\ ${ }^{3}$ Key Laboratory of Civil Engineering Structures \& Disaster Prevention, and Mitigation Technology \\ of Zhejiang Province, Hangzhou, China, 310032; \\ a 940208977@qq.com ,b hznity@zjut.edu.cn ,"c yangyang@zjut.edu.cn, \\ d707467089@qq.com ,e jtliu@zjut.edu.cn , ${ }^{\dagger}$ guchunping@zjut.edu.cn
}

*Correspondence should be addressed to Yang YANG ( yangyang@zjut.edu.cn ) or Tongyuan NI( hznity@zjut.edu.cn ).

Keywords: pervious concrete, optimization for performance, interface area, ratio of aggregate to binder, permeability

Abstract: The strength of pervious concrete is relatively lower compared with ordinary concrete because of its porosity. In this paper, three reinforcing agents were used to optimize the performance of interface area between aggregate and cemented material. Specifically, the contents of FA were weight of cement $10 \%, 15 \%, 20 \%$ to replace cement; and similarly, the contents of BS were $5 \%, 8 \%, 10 \%$; the contents of DLP were $1 \%, 3 \%, 5 \%$. The ratio of aggregate (RAB) to binder was optimized for pervious concrete strength by experiment. The results showed that the compression strength of pervious concrete can be improved by adding suitable amount reinforcing agents such as FA, BS, DLP. The permeability coefficient and porosity of pervious concrete increased with the RAB increases. And there was a good linear relationship between permeability coefficient, porosity and RAB. The test results suggested that the suitable range of FA was $10 \% \sim 15 \%$, the range of BS was around $10 \%$, and the range of DLP was $1 \% \sim 3 \%$. The results indicated that the best RAB was 3.5.

\section{Introduction}

During the past decades, permeable paving materials had been widely used as one kind of environment-friendly materials [1-4]. The permeable pavements have so many advantages such as:

(1) The rainwater can be easy to filter underground. So the groundwater resources can renew in time.

(2) It has no plash on the surface and does not glisten at night in raining days. This improves the comfort and safety of drivers.

(3) It is easy for soil to exchange heat and moisture with air. This can relieve hot island in city.

(4) It has good sound absorption property. So, it can absorb the noise of vehicles, which creates quiet and comfortable environment $[\underline{1}, \underline{3-7}]$.

The pervious concrete pavement was a kind of permeable pavements. It consists of a carefully controlled amount of paste and an aggregate system with a uniform particle size or a narrow particle size distribution and with little or no sand[]]. Owing to a lack of filling of fine aggregates, the construction of a coarse aggregate skeleton structure and the intercalation friction between aggregate contact points are important guarantees for the formation of the material strength.[9] 
Unfortunately, due to its high porosity and low cement/mortar content, pervious concrete generally has significantly reduced strength compared with conventional concrete. Some research literatures had shown that the major factors that affect pervious concrete strength include the concrete porosity, ratio of water-to-binder (w/b), paste characteristic, size and volume content of coarse aggregates[ $\underline{2}$, 8-10]. Although extensive research work has been done, most previous researcher focuses on permeability, strength, frost resistance and abrasion resistance of pervious concrete. So, some researchers began to focus on the design and performance optimization of pervious concrete[ $\underline{9}, \underline{11}]$. The paper focus on optimization for performance of pervious concrete by being added some reinforcing agent, such as strength being enhanced, the influence the ratio of aggregate to binder (RAB), permeability, et al.

\section{Materials and Experiments}

\section{Raw materials}

Cement type used in this paper is $\mathrm{P} \cdot \mathrm{O} 42.5$ in according with Chinese GB 175-2007. Three kinds of single gradation of crushed stone aggregate were used as coarse aggregate. The coarse aggregate particle sizes were $1.18 \mathrm{~mm} \sim 2.36 \mathrm{~mm}$ (type A), $2.36 \mathrm{~mm} \sim 4.75 \mathrm{~mm}$ (type B), $4.75 \mathrm{~mm}-9.5 \mathrm{~mm}$ (type C), respectively. Summary of test results of coarse aggregate were showed in table 1. (SF), fly ash (FA) and dispersible latex powder (DLP) was used as reinforcing agent for bonding materials. SF and FA were two kinds of frequently-used admixtures to improve concrete performances $[\underline{12}, \underline{13}]$. The chemical composition contents of FA were showed in table 2 and summary of physical properties of BS and DLP were showed in table 3. Poly-carboxylate super-plasticizer (SP) which prepared by Zhejiang Huawei building materials Group Co. Ltd was used as high efficiency water reducing agent in this study.

TABLE 1 Summary of test results of coarse aggregate.

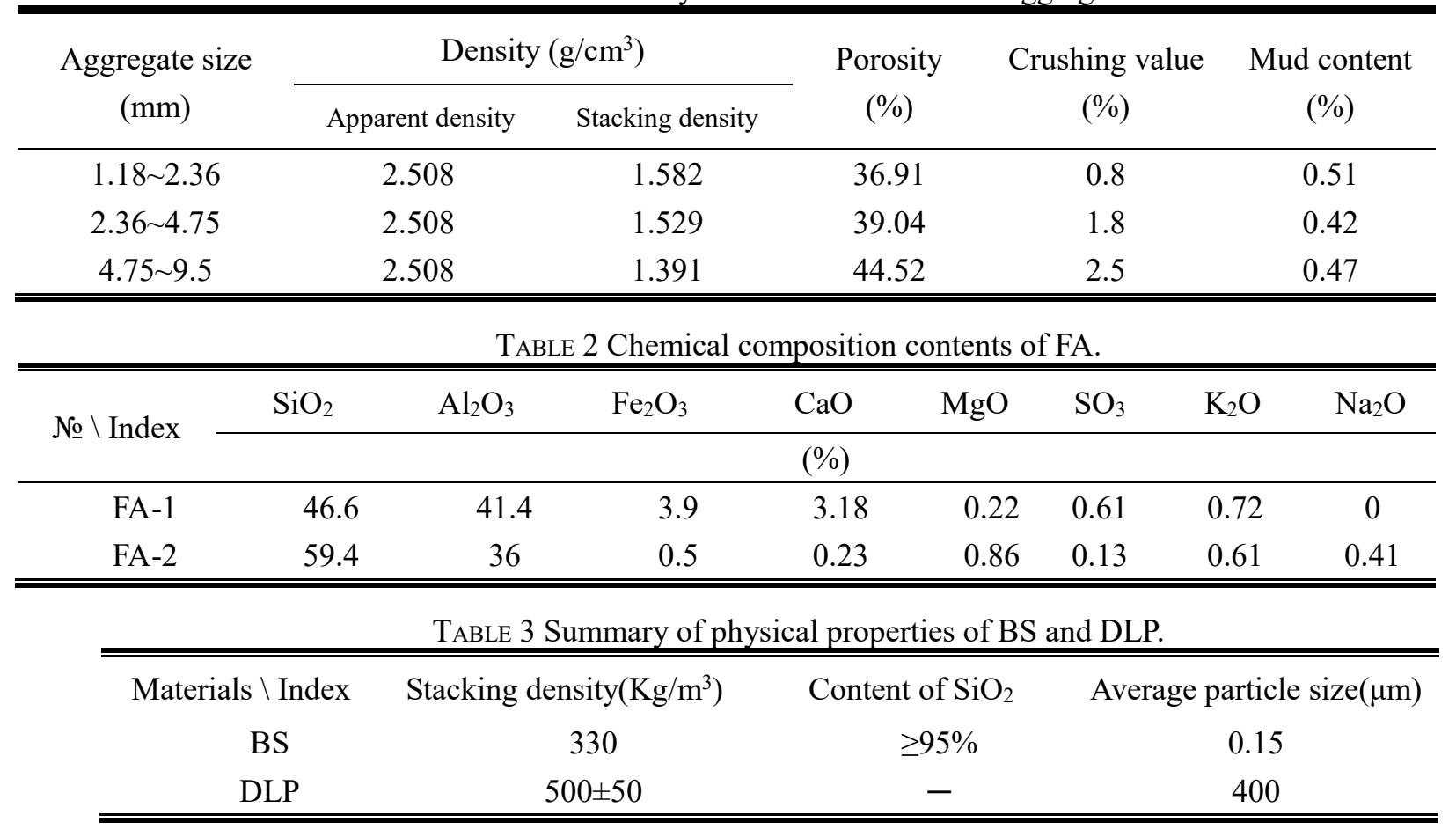

\section{Optimization for pervious concrete strength}

Pervious concrete aggregate are contacted by contact point of aggregate[2]. So, the interface area between aggregate and cemented material is the weakest part of pervious concrete. And this would 
be affected by several facts such as combination method of mixture, dosage of admixture, ratio of aggregate to binder, aggregate size and the molding method. On the basis of optimizing the interface of aggregate and cementation material and strengthening the strength of cementing layer, the strength performance of pervious concrete will be optimized. Two kinds of mineral active powder (FA and BS) and one kind of bond reinforcing agent (DLP) were used to enhance the interface strength.

\section{Optimization experiment of reinforcing agents for interface area performance}

Considering different effect of three reinforcing agents, the paper designed mix proportion with four levels, i.e. there were four levels of the three reinforcing agents' contents. Specifically, the contents of FA were weight of cement $10 \%, 15 \%, 20 \%$ to replace cement; and similarly, the contents of BS were $5 \%, 8 \%, 10 \%$; the contents of DLP were $1 \%, 3 \%, 5 \%$, respectively. The mix proportions of pervious concrete were showed in table 4.

TABLE 4 Mix proportions of pervious concrete $\left(\mathrm{kg} / \mathrm{m}^{3}\right)$

\begin{tabular}{|c|c|c|c|c|c|c|c|}
\hline № \Materials & Cement & Water & Coarse aggregate & FA & $\mathrm{BS}$ & DLP & Water reducer \\
\hline 1 & 302 & 126 & 1498 & 36 & 18 & 3.6 & 1.57 \\
\hline 2 & 293 & 126 & 1498 & 36 & 27 & 3.6 & 2.05 \\
\hline 3 & 284 & 126 & 1498 & 36 & 36 & 3.6 & 2.44 \\
\hline 4 & 295 & 126 & 1498 & 36 & 18 & 10.8 & 1.54 \\
\hline 5 & 286 & 126 & 1498 & 36 & 27 & 10.8 & 1.49 \\
\hline 6 & 277 & 126 & 1498 & 36 & 36 & 10.8 & 2.63 \\
\hline 7 & 288 & 126 & 1498 & 36 & 18 & 18 & 1.50 \\
\hline 8 & 279 & 126 & 1498 & 36 & 27 & 18 & 2.09 \\
\hline 9 & 270 & 126 & 1498 & 36 & 36 & 18 & 2.76 \\
\hline 10 & 284 & 126 & 1498 & 54 & 18 & 3.6 & 1.54 \\
\hline 11 & 275 & 126 & 1498 & 54 & 27 & 3.6 & 1.96 \\
\hline 12 & 266 & 126 & 1498 & 54 & 36 & 3.6 & 2.29 \\
\hline 13 & 277 & 126 & 1498 & 54 & 18 & 10.8 & 1.44 \\
\hline 14 & 268 & 126 & 1498 & 54 & 27 & 10.8 & 1.61 \\
\hline 15 & 259 & 126 & 1498 & 54 & 36 & 10.8 & 2.63 \\
\hline 16 & 270 & 126 & 1498 & 54 & 18 & 18 & 1.50 \\
\hline 17 & 261 & 126 & 1498 & 54 & 27 & 18 & 2.14 \\
\hline 18 & 252 & 126 & 1498 & 54 & 36 & 18 & 2.76 \\
\hline 19 & 266 & 126 & 1498 & 72 & 18 & 3.6 & 1.47 \\
\hline 20 & 257 & 126 & 1498 & 72 & 27 & 3.6 & 1.98 \\
\hline 21 & 248 & 126 & 1498 & 72 & 36 & 3.6 & 2.14 \\
\hline 22 & 259 & 126 & 1498 & 72 & 18 & 10.8 & 1.44 \\
\hline 23 & 250 & 126 & 1498 & 72 & 27 & 10.8 & 1.60 \\
\hline 24 & 241 & 126 & 1498 & 72 & 36 & 10.8 & 2.63 \\
\hline 25 & 252 & 126 & 1498 & 72 & 18 & 18 & 1.50 \\
\hline 26 & 243 & 126 & 1498 & 72 & 27 & 18 & 2.21 \\
\hline 27 & 234 & 126 & 1498 & 72 & 36 & 18 & 2.76 \\
\hline
\end{tabular}

Optimization experiment of RAB for pervious concrete strength

The ratio of aggregate to binder (RAB) is a key factor to affect characteristic performance of pervious concrete, such as strength, workability, durability and permeability.[11] Cementitious material, as important binder in pervious concrete, plays the role of bonding the structural skeleton 
formed by coarse aggregate into a whole. The level of RAB should be selected considering the strength requirements. A method of optimization of RAB is to increase the adhesion area strength, scan a suitable RAB for pervious concrete. There were different improvements to the interface area strength between aggregate and cemented material of different RAB using the same reinforcing agents' contents. So, it is necessary to determine the proper RAB to improve the strength of permeable concrete at the same time.

TABLE 5 Mix proportions of pervious concrete with different RAB $\left(\mathrm{kg} / \mathrm{m}^{3}\right)$

\begin{tabular}{ccccccccc}
\hline \hline № \Materials & RAB & Cement & Water & $\begin{array}{c}\text { Coarse } \\
\text { aggregate }\end{array}$ & FA & DLP & BS & $\begin{array}{c}\text { Water } \\
\text { reducer }\end{array}$ \\
\hline 1 & 2.9 & 408 & 181 & 1498 & 51.6 & 5.2 & 51.6 & 4.08 \\
2 & 3.2 & 370 & 164 & 1498 & 46.8 & 4.7 & 46.8 & 3.70 \\
3 & 3.5 & 338 & 150 & 1498 & 42.8 & 4.3 & 42.8 & 3.38 \\
4 & 3.8 & 311 & 138 & 1498 & 39.4 & 3.9 & 39.4 & 3.11 \\
5 & 4.1 & 284 & 126 & 1498 & 36.0 & 3.6 & 36.0 & 2.84 \\
\hline \hline
\end{tabular}

\section{Results and discussion}

\section{Optimization analysis of reinforcing agent for interface area performance}

The compressive strength test results of pervious concrete with three compound reinforcing agents at $7 d, 14 d, 28 d$ ages were shown in Fig.1- Fig.3.

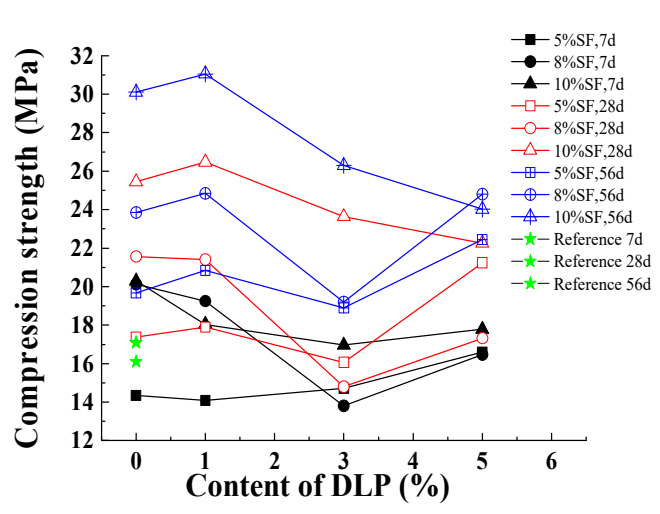

Fig. 1 Compression strength using three reinforcing agents. $10 \% \mathrm{FA}$

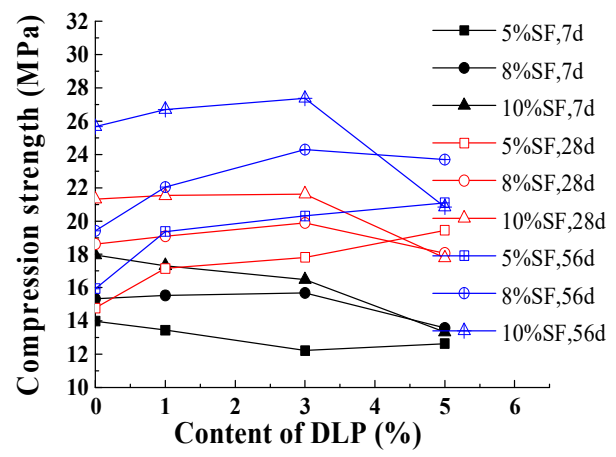

Fig. 3 Compression strength using three reinforcing agents. $20 \% \mathrm{FA}$.

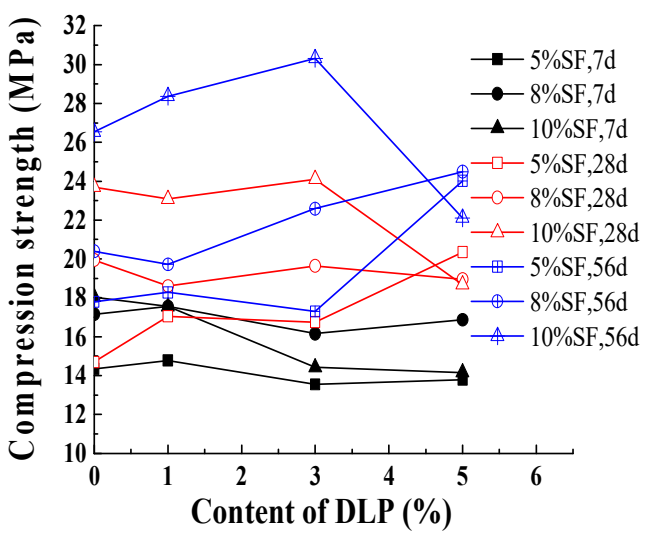

Fig. 2 Compression strength using three reinforcing agents. $15 \% \mathrm{FA}$

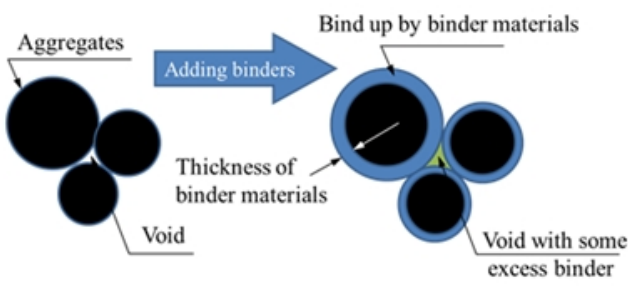

Fig. 4 Sketch map of aggregate bind up by binder materials

The results of Fig. 1 showed that the compression strength of pervious concrete was $31.1 \mathrm{MPa}$ at 56d age, which concrete containing 10\% FA, 10\% BS, and 1\% DLP. The strength increased by 
13.2MPa compared with the reference group. Similarly, the compression strength was $30.3 \mathrm{MPa}$ at 56d age (Fig.2), which concrete containing 15\% FA, 10\% BS, and 3\% DLP, and the strength increased by $12.5 \mathrm{MPa}$ compared with the reference group. But, the compression strength was $27.4 \mathrm{MPa}$ at $56 \mathrm{~d}$ age (Fig.3), which concrete containing 20\% FA, 10\% BS, and 3\% DLP. It was lower than the first two groups. So, the researcher of this paper suggested that the suitable range of FA was $10 \% \sim 15 \%$, the range of BS was around $10 \%$, and the range of DLP was $1 \% \sim 3 \%$.

\section{Optimization analysis of RAB for pervious concrete strength}

The RAB is one of important factors to pervious concrete strength[14]. The Fig 4 showed that the sketch map of aggregate bind up by binder materials. The parameter RAB reflects the aggregates in concrete bind up by binder materials. So, it was an important works that optimization analysis of RAB for pervious concrete strength.

The results of Fig.5 showed that the compressive strength of pervious concrete decreases while increases of RAB. The strength of pervious concrete at $56 \mathrm{~d}$ age reached $37 \mathrm{MPa}$, while the RAB was 3.5 , and the strength can meet the target requirement of CIJ/T 135-2009[15]. The permeability coefficient and porosity of pervious concrete increase while increases of RAB. The strength of pervious concrete reached $41.2 \mathrm{MPa}$ as the RAB was 2.9 , but the permeability coefficient tends to 0 . The compressive strength of specimen increases gradually with the decrease of RAB, but the permeability coefficient decreases greatly. The voids would be filled with some excess binder materials. And the excess binder materials would block up some connected pore (Fig.4). The connect pore changed narrow and the number of that changed small. So, permeability coefficient and porosity decreased. The results also showed that there was a good linear relationship between permeability coefficient, porosity and RAB (Fig.6). This was due to the increase of binder content, and the bonding condition between the aggregates changed from point contact to surface contact. But this would be lead to the number and pore size of the connected pores decrease. At the same time, binder slurry materials have a certain rheological property at early ages. It would cause the slurry to sink while the increase of binder content and cause the bottom pore to be blocked. The results indicated that the best $\mathrm{RAB}$ was 3.5.

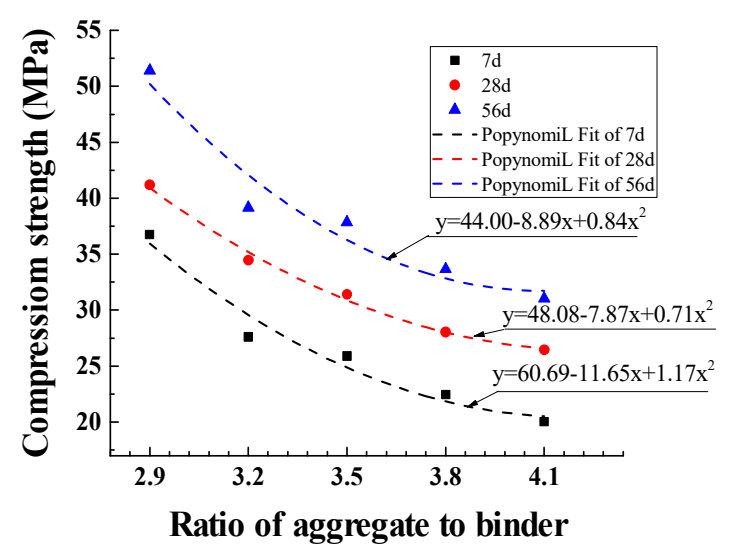

Fig.5 Influence of RAB on compression strength of pervious concrete

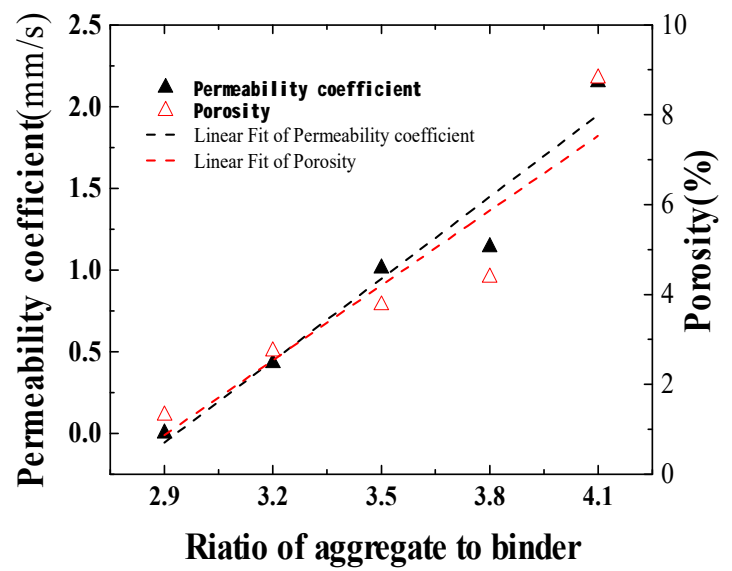

Fig. 6 Influence of ratio of aggregate to binder on permeability coefficient

\section{Permeability of pervious concrete mixed by optimum proportion}

The permeability of pervious concrete was first performance index[16]. Table 5 showed the tests results of permeability, effective porosity of concrete with reinforcing agents. The permeability coefficient of pervious concrete can be improved by the addition of proper amount of FA and BS, but the permeability coefficient and effective porosity decreases obviously while the amount of FA was greater than $20 \%$, and that of BS greater $8 \%$. The permeability coefficient of each group was greater than $0.5 \mathrm{~mm} / \mathrm{s}$, and that of the optimum strength group was $1.94 \mathrm{~mm} / \mathrm{s}$, which meets the water permeability requirement of CIJ/T 135-2009[15]. 
The permeability coefficient and porosity of pervious concrete increased with the RAB increases. The results showed that there was a good linear relationship between permeability coefficient, porosity and RAB (Fig.6).

\begin{tabular}{|c|c|c|c|c|c|}
\hline № Materials, index & $\begin{array}{c}\text { Content of FA } \\
(\%)\end{array}$ & $\begin{array}{c}\text { Content of BS } \\
(\%)\end{array}$ & $\begin{array}{c}\text { Content of DLP } \\
(\%)\end{array}$ & $\begin{array}{l}\text { Permeability } \\
\text { coefficient } \\
(\mathrm{mm} / \mathrm{s})\end{array}$ & $\begin{array}{c}\text { Effective porosity } \\
(\%)\end{array}$ \\
\hline 1 & 10 & 5 & 0 & 4.2 & 16.0 \\
\hline 2 & 15 & 5 & 0 & 5.8 & 18.2 \\
\hline 3 & 20 & 5 & 0 & 5.1 & 18.5 \\
\hline 4 & 10 & 8 & 0 & 3.2 & 14.4 \\
\hline 5 & 15 & 8 & 0 & 3.3 & 15.5 \\
\hline 6 & 20 & 8 & 0 & 3.0 & 14.7 \\
\hline 7 & 10 & 10 & 0 & 1.9 & 9.5 \\
\hline 8 & 15 & 10 & 0 & 2.3 & 12.6 \\
\hline 9 & 20 & 10 & 0 & 2.3 & 10.8 \\
\hline 10 & 10 & 0 & 1 & 3.4 & 15.2 \\
\hline 11 & 15 & 0 & 1 & 3.6 & 15.3 \\
\hline 12 & 20 & 0 & 1 & 3.5 & 15.9 \\
\hline 13 & 10 & 0 & 3 & 3.0 & 13.4 \\
\hline 14 & 15 & 0 & 3 & 3.3 & 15.5 \\
\hline 15 & 20 & 0 & 3 & 3.2 & 13.5 \\
\hline 16 & 10 & 0 & 5 & 2.7 & 14.5 \\
\hline 17 & 15 & 0 & 5 & 3.0 & 14.8 \\
\hline 18 & 20 & 0 & 5 & 3.2 & 15.7 \\
\hline 19 & 0 & 5 & 1 & 4.0 & 14.1 \\
\hline 20 & 0 & 5 & 3 & 4.0 & 14.7 \\
\hline 21 & 0 & 5 & 5 & 2.1 & 13.1 \\
\hline 22 & 0 & 8 & 1 & 2.4 & 8.5 \\
\hline 23 & 0 & 8 & 3 & 1.8 & 6.2 \\
\hline 24 & 0 & 8 & 5 & 1.4 & 7.0 \\
\hline 25 & 0 & 10 & 1 & 2.3 & 6.7 \\
\hline 26 & 0 & 10 & 3 & 1.8 & 6.2 \\
\hline 27 & 0 & 10 & 5 & 1.4 & 6.3 \\
\hline
\end{tabular}

\section{Conclusions}

The following conclusions can be obtained in the scope of this study:

(1) The compression strength of pervious concrete can be improved by adding suitable amount reinforcing agents such as FA, BS, DLP. The test results suggested that the suitable range of FA was $10 \% \sim 15 \%$, the range of BS was around $10 \%$, and the range of DLP was $1 \% \sim 3 \%$.

(2) The permeability coefficient and effective porosity decreases obviously while the amount of FA was greater than $20 \%$, and that of BS greater $8 \%$.

(3) The permeability coefficient and porosity of pervious concrete increased with the RAB increases. And there was a good linear relationship between permeability coefficient, porosity and RAB. The results indicated that the best RAB was 3.5. 


\section{Acknowledgement}

This research work was supported by the Department of housing and urban-rural development of Zhejiang Provionce (2015K99), and financially supported by Hangzhou Metro-East Construction Investment Co. Ltd., Zhejiang City Construction Engineering Supervision Co. Ltd.

\section{References}

[1] Jing Yang and Guoliang Jiang, Experimental study on properties of pervious concrete pavement materials, Cement \& Concrete Research, vol. 33, pp. 381-386, 2003.

[2] Yu Chen, Kejin Wang, Xuhao Wang, and Wenfang Zhou, Strength, fracture and fatigue of pervious concrete, Construction \& Building Materials, vol. 42, pp. 97-104, 2013.

[3] Tong Yuan Ni, Chen Hui Jiang, Hui Xing Tai, and Guo Qing Zhao, Experimental Study on Sound Absorption Property of Porous Concrete Pavement Layer, Applied Mechanics \& Materials, vol. 507, pp. 238-241, 2014.

[4] TongYuan Ni, Yang Yang, Deyu Kong, ChengChang Ma, and Cheng Fang, Temperature Variation of Porous Asphalt Pavement under Hangzhou Climate Circumstances, Urban Environment \& Urban Ecology, vol. 22, pp. 42-44, 2009.

[5] Baoshan Huang, Hao Wu, Xiang Shu, and Edwin G. Burdette, Laboratory evaluation of permeability and strength of polymer-modified pervious concrete, Construction \& Building Materials, vol. 24, pp. 818-823, 2010.

[6] Hanh Nguyen Dang, Nassim Sebaibi, Mohamed Boutouil, Lydia Leleyter, and Fabienne Baraud, A modified method for the design of pervious concrete mix, Construction \& Building Materials, vol. 73, pp. 271-282, 2014.

[7] Tongyuan $\mathrm{Ni}$ and Kanghu $\mathrm{Hu}$, Permeability test of pervious concrete in different rainfall, in International Conference on Mechanic Automation \& Control Engineering, 2011, pp. 5102-5104.

[8] Jingru Yu, Tongyuan $\mathrm{Ni}$, Yang Yang, Liangying $\mathrm{Xu}$, and Feng He, Research Progress of Permeable Pavement Layer, Urban Roads Bridges \& Flood Control, pp. 19-25, 2017.

[9] Ailing Yao, Hao Ding, Xiaochen Zhang, Zhao Hu, Runshu Hao, and Tao Yang, Optimum Design and Performance of Porous Concrete for Heavy-Load Traffic Pavement in Cold and Heavy Rainfall Region of NE China, Advances in Materials Science \& Engineering, vol. 2018, pp. 1-15, 2018.

[10] M. Sonebi and M. T. Bassuoni, Investigating the effect of mixture design parameters on pervious concrete by statistical modelling, Construction \& Building Materials, vol. 38, pp. 147-154, 2013.

[11] S Ahmad and S. A. Alghamdi, A statistical approach to optimizing concrete mixture design, TheScientificWorldJournal, vol. 2014, p. 561539, 2014.

[12] Tongyuan Ni, Yang Yang, Dandan Wu, and Chenhui Jiang, Influences of Environmental Conditions on the Cracking Tendency of Dry-Mixed Plastering Mortar, Advances in Materials Science and Engineering, vol. 10.1155/2018/9160801, p. 9, 2018.

[13] M. Mazloom, A. A. Ramezanianpour, and J. J. Brooks, Effect of silica fume on mechanical properties of high-strength concrete, Cement \& Concrete Composites, vol. 26, pp. 347-357, 2004.

[14] Anthony Torres, Jiong $\mathrm{Hu}$, and Amy Ramos, The effect of the cementitious paste thickness on the performance of pervious concrete, Construction \& Building Materials, vol. 95, pp. 850-859, 2015.

[15] CIJ/T 135-2009, Technical Specifications for Pervious Concrete Pavement, ed. Beijing: 
China Architecture \& Building Press., 2009.

[16] Hassan Tajik Ghashghaei and Abolfazl Hassani, Investigating the Relationship between Porosity and Permeability Coefficient for Pervious Concrete Pavement by Statistical Modelling, Materials Sciences \& Applications, vol. 07, pp. 101-107, 2016. 